\title{
Article \\ Enzymatic Degradation of Multiple Major Mycotoxins by Dye-Decolorizing Peroxidase from Bacillus subtilis
}

\author{
Xing Qin, Xiaoyun Su, Tao Tu (D), Jie Zhang (D), Xiaolu Wang, Yaru Wang, Yuan Wang, Yingguo Bai, Bin Yao, \\ Huiying Luo * and Huoqing Huang *
}

\begin{abstract}
State Key Laboratory of Animal Nutrition, Institute of Animal Sciences, Chinese Academy of Agricultural Sciences, Beijing 100193, China; qinxing@caas.cn (X.Q.); suxiaoyun@caas.cn (X.S.); tutao@caas.cn (T.T.); zhangjie09@caas.cn (J.Z.); wangxiaolu@caas.cn (X.W.); wangyaru@caas.cn (Y.W.); wangyuan08@caas.cn (Y.W.); baiyingguo@caas.cn (Y.B.); yaobin@caas.cn (B.Y.)

* Correspondence: luohuiying@caas.cn (H.L.); huanghuoqing@caas.cn (H.H.)
\end{abstract}

Citation: Qin, X.; Su, X.; Tu, T.; Zhang, J.; Wang, X.; Wang, Y.; Wang, Y.; Bai, Y.; Yao, B.; Luo, H.; et al. Enzymatic Degradation of Multiple Major Mycotoxins by Dye-Decolorizing Peroxidase from Bacillus subtilis. Toxins 2021, 13, 429. https://doi.org/ $10.3390 /$ toxins 13060429

Received: 20 May 2021

Accepted: 16 June 2021

Published: 19 June 2021

Publisher's Note: MDPI stays neutral with regard to jurisdictional claims in published maps and institutional affiliations.

Copyright: (C) 2021 by the authors. Licensee MDPI, Basel, Switzerland. This article is an open access article distributed under the terms and conditions of the Creative Commons Attribution (CC BY) license (https:/ / creativecommons.org/licenses/by/ $4.0 /)$.

\begin{abstract}
The co-occurrence of multiple mycotoxins, including aflatoxin $\mathrm{B}_{1}\left(\mathrm{AFB}_{1}\right)$, zearalenone (ZEN) and deoxynivalenol (DON), widely exists in cereal-based animal feed and food. At present, most reported mycotoxins degrading enzymes target only a certain type of mycotoxins. Therefore, it is of great significance for mining enzymes involved in the simultaneous degradation of different types of mycotoxins. In this study, a dye-decolorizing peroxidase-encoding gene BsDyP from Bacillus subtilis SCK6 was cloned and expressed in Escherichia coli BL21/pG-Tf2. The purified recombinant BsDyP was capable of oxidizing various substrates, including lignin phenolic model compounds 2,6-dimethylphenol and guaiacol, the substrate 2,2'-azino-bis (3-ethylbenzothiazoline-6-sulfonic acid), anthraquinone dye reactive blue 19 and azo dye reactive black 5, as well as $\mathrm{Mn}^{2+}$. In addition, BsDyP could efficiently degrade different types of mycotoxins, including $\mathrm{AFB}_{1}, \mathrm{ZEN}$ and $\mathrm{DON}$, in presence of $\mathrm{Mn}^{2+}$. More important, the toxicities of their corresponding enzymatic degradation products $\mathrm{AFB}_{1}{ }^{-}$ diol, 15-OH-ZEN and $\mathrm{C}_{15} \mathrm{H}_{18} \mathrm{O}_{8}$ were significantly lower than $\mathrm{AFB}_{1}, \mathrm{ZEN}$ and DON. In summary, these results proved that $B s \mathrm{DyP}$ was a promising candidate for the simultaneous degradation of multiple mycotoxins in animal feed and food.
\end{abstract}

Keywords: dye-decolorizing peroxidase; mycotoxin; aflatoxin $\mathrm{B}_{1}$; zearalenone; deoxynivalenol; biotransformation

Key Contribution: BsDyP could degrade multiple major mycotoxins including $\mathrm{AFB}_{1}, \mathrm{ZEN}$ and DON through the catalytic oxidation of $\mathrm{Mn}^{2+}$. The predicted biological toxicity of each corresponding degradation product was significantly removed.

\section{Introduction}

Mycotoxins are a diverse group of toxic secondary metabolites produced by certain filamentous fungi, and they display carcinogenicity, teratogenicity, immune toxicity, neurotoxicity, hepatotoxicity, nephrotoxicity, reproductive and developmental toxicity towards humans and animals [1]. Until now, more than 400 mycotoxins have been identified and reported; however, only a few mycotoxins dominate in contaminated food and animal feed. These are aflatoxins $\mathrm{B}_{1}\left(\mathrm{AFB}_{1}\right)$, zearalenone $(\mathrm{ZEN})$, deoxynivalenol (DON), ochratoxin $A$, fumonisin B1, citrinin and patulin [2,3]. Meanwhile, the co-occurrence of abovementioned major mycotoxins is frequently observed in cereal-based animal feed and food [4,5], which might lead to synergistic and additive toxicological effects in humans and animals due to different mechanisms of action of mycotoxins at the cellular level [6].

The control of mycotoxins in food and feed depends on two main approaches: the prevention of mycotoxin production and detoxification of mycotoxins [7,8]. Most agronomic, physical and chemical strategies at pre-harvest as well as at post-harvest have been shown to be rather ineffective to control mycotoxin contamination [8]. With the increasing 
demand for effective approaches to reducing mycotoxin contamination, researchers have been paying more attention to biological strategies. The detoxification of mycotoxins through biotransformation by microorganisms or their enzymes has gradually become one of the most promising strategies because of its advantages in efficiency, specificity and environmental friendliness $[7,9]$. As for biotransformation of multiple mycotoxins, several microorganisms such as Bacillus subtilis, Rhodococcus percolatus and Pseudomonas putida have been reported to be capable of degrading $\mathrm{AFB}_{1}$ and $\mathrm{ZEN}$ [7,10-12]. In contrast, only a few enzymes have been identified, purified and characterized for multiple mycotoxin biotransformation.

Considering that part of mycotoxins is structurally similar to a lignin monomer or its derivatives, ligninolytic enzymes might be able to degrade different types of mycotoxins. In our previous study, we found that fungal manganese peroxidases could degrade four major mycotoxins, namely $\mathrm{AFB}_{1}, \mathrm{ZEN}, \mathrm{DON}$ and fumonisin $\mathrm{B}_{1}$, in the presence of a dicarboxylic acid malonate [13]. Moreover, bacterial and fungal laccases could simultaneously degrade $\mathrm{AFB}_{1}$ and $\mathrm{ZEN}$, using the laccase/mediator systems [14]. In this study, another ligninolytic enzyme dye-decolorizing peroxidase (DyP) from B. subtilis SCK6 was expressed in Escherichia coli, using the cold shock-inducible expression system coupled with co-expression of chaperones. Then the substrate specificity of purified recombinant $B s \mathrm{DyP}$ was characterized. Moreover, the degrading capacity of three major mycotoxins $\mathrm{AFB}_{1}, \mathrm{ZEN}$ and $\mathrm{DON}$ by BsDyP was evaluated, and corresponding enzymatic degradation products were identified by mass spectrometry analysis.

\section{Results and Discussion}

\subsection{Gene Cloning, Expression and Purification of BsDyP from B. subtilis SCK6}

It has been reported that $B$. subtilis could be able to efficiently degrade different types of mycotoxins, including $\mathrm{AFB}_{1}$ and $\mathrm{ZEN}[15,16]$. However, very few mycotoxins-degrading enzymes are identified and characterized except for CotA laccase [14]. In the present study, genomic analysis of B. subtilis SCK6 revealed that ligninolytic enzymes were composed of DyP and laccase based on the PeroxiBase and CAZy databases annotation. One DyP gene, $1251 \mathrm{bp}$, was identified in the genome of B. subtilis SCK6, which encoded 416 amino acids with an estimated molecular weight of $45.7 \mathrm{kDa}$ and an isoelectric point value of 8.71 . The cloned BsDyP from B. subtilis SCK6 shared 93\% nucleic acid sequence identity and 96\% amino acid identity with BsDyP from B. subtilis KCTC2023 [17].

E. coli, one of the most popular hosts for recombinant protein overexpression, was used as the expressing host to heterologously express BsDyP. Given that the ligninolytic enzyme DyP expressed in E. coli accumulated in inclusion bodies which required another refolding process [18-20], the cold shock-inducible expression system coupled with co-expression of chaperones was applied to obtain the active DyP. With the help of molecular chaperones groES, groEL and tig, BsDyP was successfully expressed in E. coli BL21 as a soluble form. A significant activity of DyP was detected in the sonicated cell supernatant, indicating the proper formation of disulfide bonds and heme incorporation into recombinant BsDyP. After purification by immobilized metal affinity chromatography, BsDyP showed a single band on SDS-PAGE gel, corresponding to the calculated molecular masses (Figure 1a). 
a

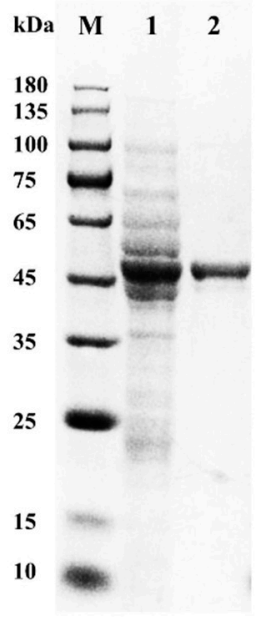

b

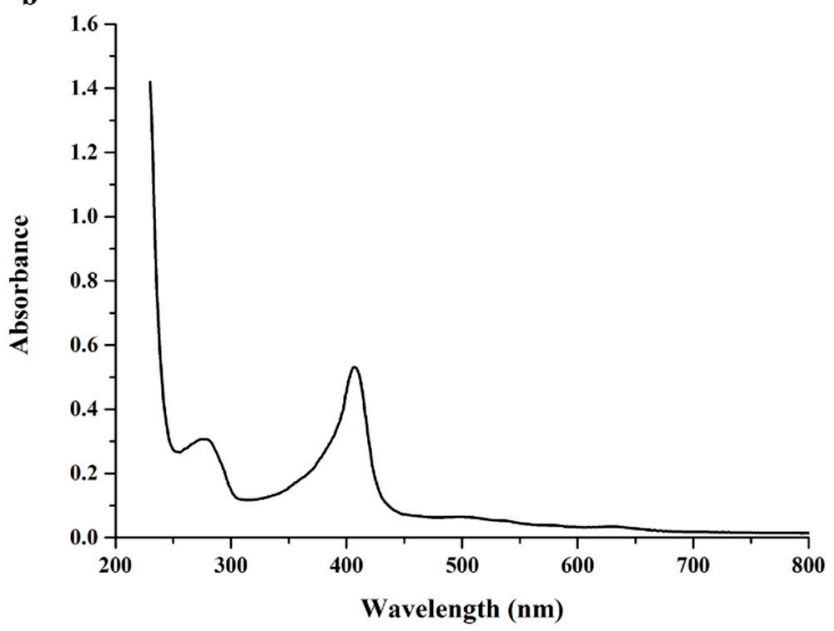

Figure 1. The analysis of purified recombinant BsDyP by SDS-PAGE (a) and UV-visible spectroscopy (b). Lanes: $M$, the protein molecular mass marker; 1 , the whole-cell lysis protein; 2 , the purified recombinant $B s \mathrm{DyP}$.

\subsection{Biochemical Characterization of the Purified Recombinant BsDyP}

Like other ligninolytic peroxidases, including manganese peroxidase, versatile peroxidase and lignin peroxidase, DyP also showed the typical features of heme-containing enzymes with a Soret peak at 404-408 nm [21]. As shown in Figure 1b, BsDyP had an obvious absorbance peak at $407 \mathrm{~nm}$, indicating that the heme group was indeed incorporated into the purified recombinant $B s \mathrm{DyP}$. The $\mathrm{Rz}\left(\mathrm{A}_{407} / \mathrm{A}_{280}\right)$ ratio of the purified $B s \mathrm{DyP}$ was 1.7.

It had been reported that DyP could act on a broad range of substrates, including lignin-derived phenolic and non-phenolic compounds, synthetic high redox potential anthraquinone and azo dyes [19,22]. In order to explore its substrate specificity, BsDyP was tested on a series of lignin-derived compounds, synthetic dyes and $\mathrm{Mn}^{2+}$. The purified recombinant $B s$ DyP could oxidize the model substrate ABTS, phenolic compounds DMP and GUA, anthraquinone dye RB19, azo dye RB5 and $\mathrm{Mn}^{2+}$ except for the non-phenolic compound VA (Figure 2). Notably, BsDyP had the ability to oxidize $\mathrm{Mn}^{+}$to $\mathrm{Mn}^{3+}$, which belongs to the catalytic properties of manganese peroxidase and versatile peroxidase $[23,24]$. The results suggested that $B s \mathrm{DyP}$ might also contain the manganese binding sites.

In addition, the optimum $\mathrm{pHs}$ of the purified recombinant $B s \mathrm{DyP}$ oxidizing various substrates, including ABTS, DMP, GUA, RB19 and $\mathrm{Mn}^{2+}$, were all 4.0, except that a higher optimum $\mathrm{pH}$ of $\mathrm{BsDyP}$ against RB5 was 6.0. Meanwhile, BsDyP was completely inactive when the $\mathrm{pH}$ was below 3.0, which was different from fungal DyP with a wider acidic $\mathrm{pH}$ range [22,25]. The specific activity of BsDyP for ABTS, DMP, GUA, RB19 and $\mathrm{Mn}^{2+}$ at optimum $\mathrm{pH}$ were $7.25,1.79,0.03,0.67$ and $0.46 \mathrm{U} / \mathrm{mg}$, respectively. Like other dye-decolorizing peroxidases, DyPs from Pseudomonas putida, Thermobifida fusca and Thermomonospora curvata showed higher specific activities towards ABTS and RB19, exhibiting two orders of magnitude higher than that of GUA $[17,26,27]$. However, the reason for difference in specific activities towards different substrates had not been well elucidated yet. 
a

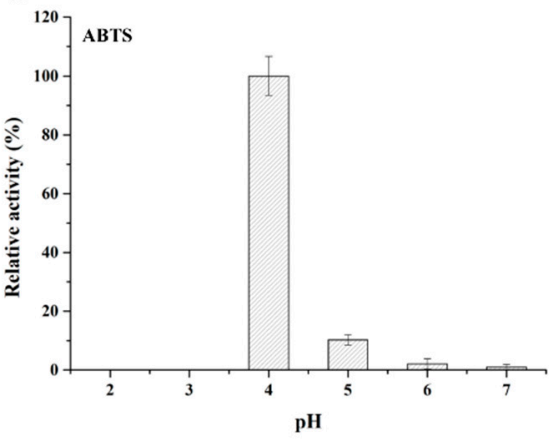

d

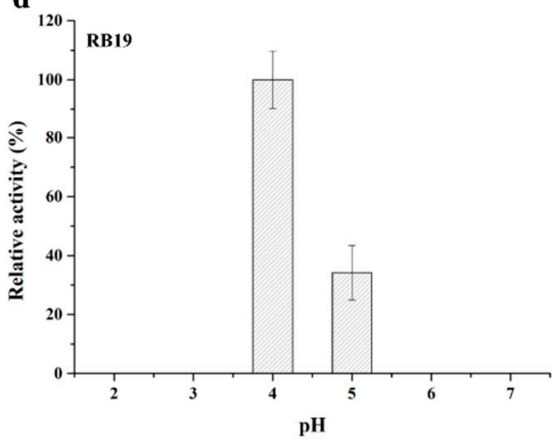

b
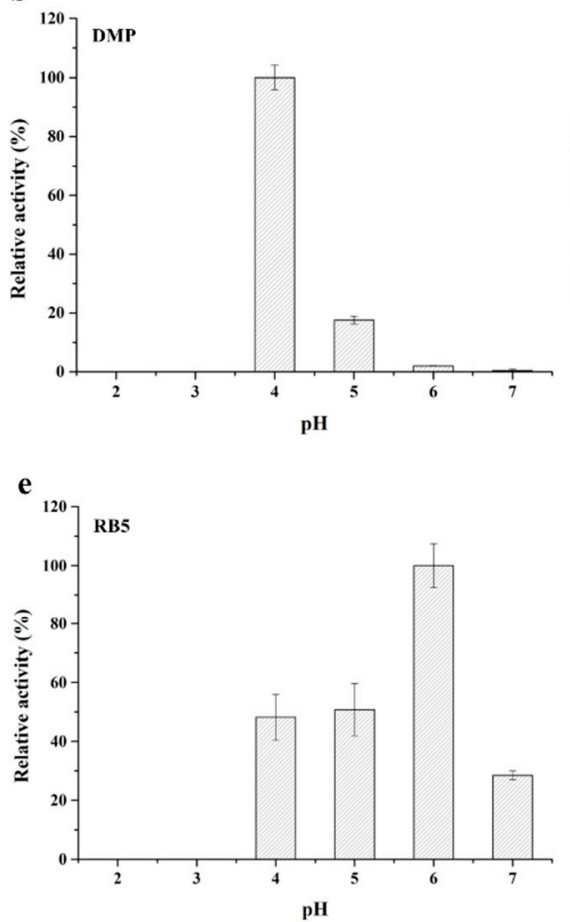

c

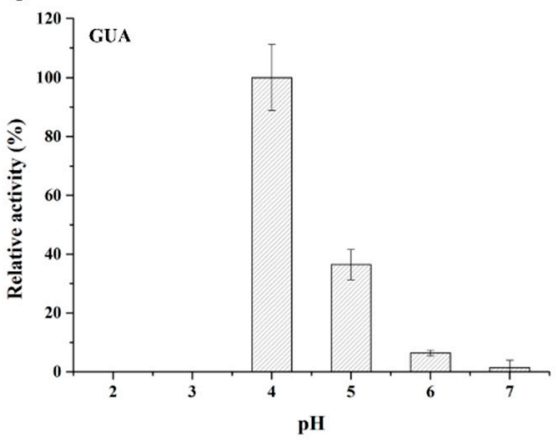

f

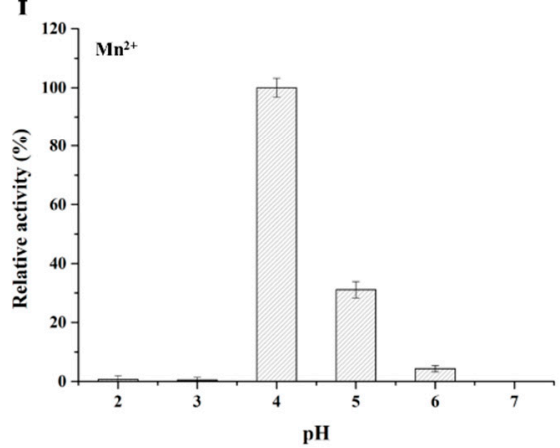

Figure 2. Optimum $\mathrm{pH}$ of the purified recombinant $B s \mathrm{DyP}$ oxidizing different substrates: ABTS (a), DMP (b), GUA (c), RB19 (d), RB5 (e) and $\mathrm{Mn}^{2+}$ (f). Each assay was performed with three independent biological replicates.

\subsection{Degradation of Different Types of Mycotoxins by BsDyP}

Although DyP was reported to be involved in lignin degradation, industrial dyes decolorization $[21,28]$, the great application value of DyP in xenobiotic bioremediation gradually attracted more and more attentions in recent years $[29,30]$. In this study, the different types of mycotoxins including $\mathrm{AFB}_{1}, \mathrm{ZEN}$ and $\mathrm{DON}$ were used to evaluate the mycotoxin degrading capability of BsDyP from B. subtilis SCK6. As shown in Figure 3, $B s$ DyP could efficiently degrade multiple mycotoxins in presence of $\mathrm{Mn}^{2+}$. $\mathrm{AFB}_{1}, \mathrm{ZEN}$ and DON were degraded up to $76.93 \%, 84.65 \%$ and $78.42 \%$ by the purified $B s D y P$ within $48 \mathrm{~h}$, respectively. Unlike $\mathrm{AFB}_{1}$ and $\mathrm{DON}$, ZEN also could be slightly degraded $11.78 \%$ by $B s D y P$ in absence of $\mathrm{Mn}^{2+}$, indicating that there might be two different mechanisms of ZEN degradation by BsDyP. On one hand, it was similar to the detoxification mechanism of manganese peroxidases that oxidized $\mathrm{Mn}^{3+}$ and malonate acid mediated degradation of mycotoxins through the formation of radicals [13]. On the other hand, ZEN might be directly degraded by binding to the catalytic pocket of $B s D y P$.

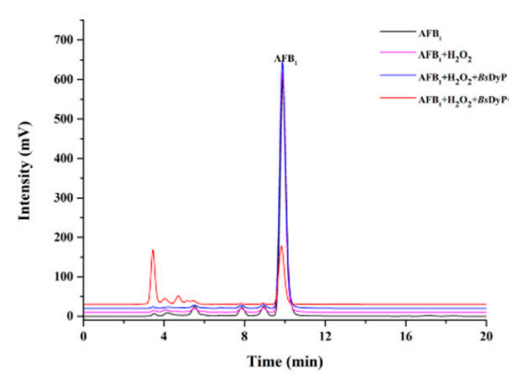

b

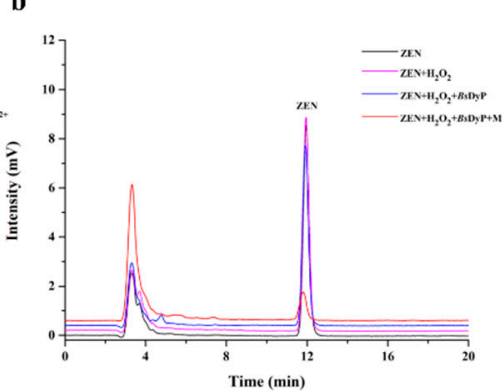

c

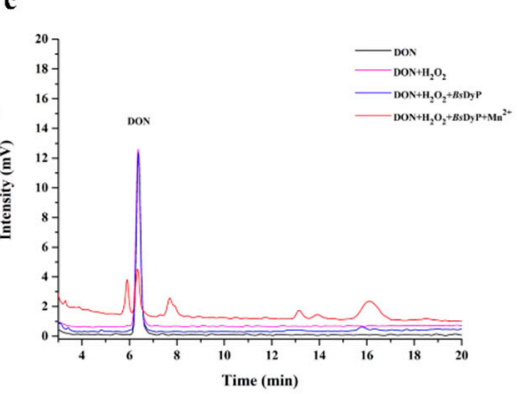

Figure 3. Degradation of different mycotoxins including $\mathrm{AFB}_{1}(\mathbf{a}), \mathrm{ZEN}(\mathbf{b})$ and $\mathrm{DON}$ (c) by $1.25 \mathrm{U} / \mathrm{mL} \mathrm{BsDyP}$ in $50 \mathrm{mM}$ malonate buffer ( $\mathrm{pH} 4.0)$ at $30^{\circ} \mathrm{C}$ for $48 \mathrm{~h}$. 
The time courses of $\mathrm{AFB}_{1}, \mathrm{ZEN}$ and DON degradation by $\mathrm{BsDyP}$ in presence of $\mathrm{Mn}^{2+}$ were shown in Figure 4. The degrading percentages of $\mathrm{AFB}_{1}$ and $\mathrm{ZEN}$ were $10.68 \%$ and $11.78 \%$ at $6 \mathrm{~h}$, and then gradually ascended to $17.37 \%$ and $43.84 \%$ at $12 \mathrm{~h}$. More than $50 \% \mathrm{AFB}_{1}$ and $\mathrm{ZEN}$ degradation occurred after a $24 \mathrm{~h}$ incubation. In contrast, the initial degradation of DON was slower, with degradation percentages of $1.99 \%$ at $6 \mathrm{~h}$, but DON content was significantly decreased at $12 \mathrm{~h}$, and then $46.56 \%$ DON was degraded over $24 \mathrm{~h}$ of incubation.
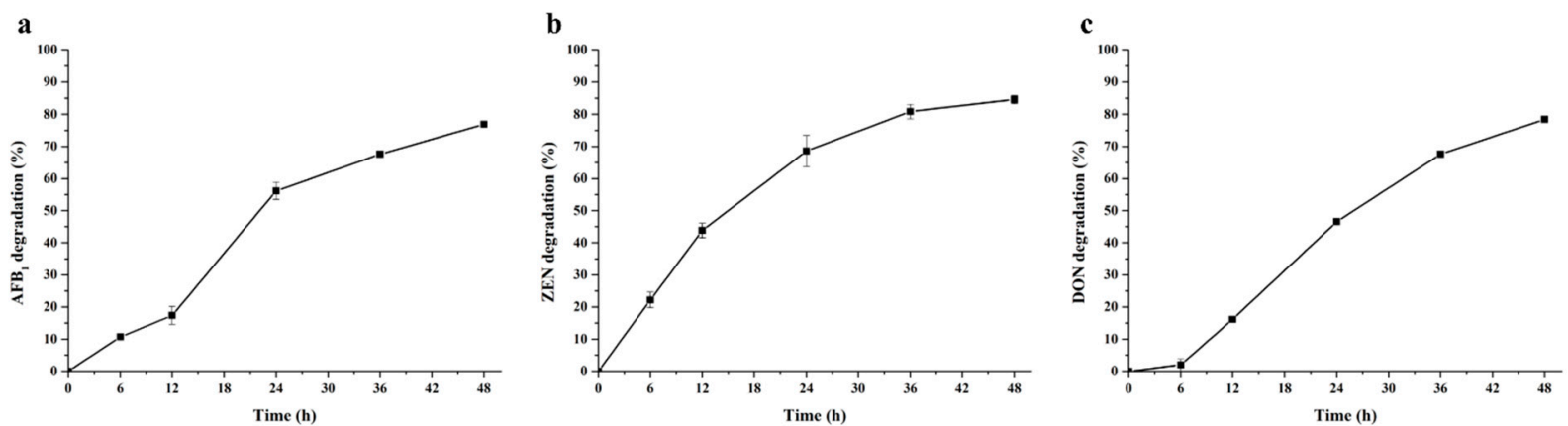

Figure 4. Time-course analysis of AFB1 (a), ZEN (b) and DON (c) by $1.25 \mathrm{U} / \mathrm{mL}$ BsDyP in $50 \mathrm{mM}$ malonate buffer (pH 4.0) supplemented with $1 \mathrm{mM} \mathrm{MnSO}_{4}$ and $0.1 \mathrm{mM} \mathrm{H}_{2} \mathrm{O}_{2}$ at $30^{\circ} \mathrm{C}$. Each assay was performed with three independent biological replicates.

\subsection{Identification of $A F B_{1}, Z E N$ and DON Degradation Products}

In order to further prove the effective detoxification of multiple mycotoxins by BsDyP, it is necessary to identify the corresponding degradation products of mycotoxins and analyze their biological toxicities. Based on the clear relationship between chemical structure and biological activities of $\mathrm{AFB}_{1}, \mathrm{ZEN}$ and $\mathrm{DON}$ [31,32], the toxicology of degradation products could judge from chemical structure changes of different mycotoxins.

The main degradation product of $\mathrm{AFB}_{1}$ was identified by LC-MS/MS. The parent ion appeared at $\mathrm{m} / \mathrm{z} 347.07[\mathrm{M}+\mathrm{H}]^{+}$and produced daughter ions of $329.06[\mathrm{M}-18+\mathrm{H}]^{+}$, $301.07[\mathrm{M}-46+\mathrm{H}]^{+}$and $273.08[\mathrm{M}-74+\mathrm{H}]^{+}$(Figure 5a). These daughter ions were in accordance with the MS/MS fragments of $\mathrm{AFB}_{1}$-diol [33], suggesting that the $\mathrm{C}_{8-9}$ double bond of terminal furan rings in $\mathrm{AFB}_{1}$ was oxidized by $B s \mathrm{DyP}$ and two hydroxyl groups were added to the molecular generate $\mathrm{AFB}_{1}$-diol. Remarkably, $\mathrm{AFB}_{1}$-diol was less toxic than $\mathrm{AFB}_{1}$ due to the removal of double bond in the terminal furan ring, which was considered as the basis for toxic and carcinogenic activity [32,34]. Similarly, the manganese peroxidase from the white rot fungus Phanerochaete sordida YK-624 could convert AFB 1 to $\mathrm{AFB}_{1}$-diol and effectively remove the mutagenic activity of $\mathrm{AFB}_{1}$ [35]. Manganese peroxidases from the white rot fungus Irpex lacteus $\mathrm{CD} 2$ were able to oxidize $\mathrm{AFB}_{1}$ to $\mathrm{AFB}_{1}-8,9$-epoxide as the intermediate product [13]. Thus, the epoxidation and hydrolysis of $\mathrm{AFB}_{1}$ to produce $\mathrm{AFB}_{1}$-diol might be the common characteristic of $\mathrm{AFB}_{1}$ degradation by $\mathrm{Mn}^{3+}$ derived radicals.

The mass spectrum for the corresponding degradation product of ZEN is shown in Figure $5 \mathrm{~b}$. Daughter ions were obtained by fragmenting the parent ion with $\mathrm{m} / \mathrm{z} 335.30$ $[\mathrm{M}+\mathrm{H}]^{+}$, including $317.15[\mathrm{M}-18+\mathrm{H}]^{+}$and $205.05[\mathrm{M}-130+\mathrm{H}]^{+}$. These daughter ions were in agreement with the MS/MS fragments of 15-OH-ZEN [33], indicating that ZEN was hydroxylated at the $\mathrm{C}_{15}$ position of aromatic moiety by $B s \mathrm{DyP}$ and $15-\mathrm{OH}-$ ZEN was the major degradation product. The result revealed that there were significant differences between DyP and the well-known ZEN degrading enzyme lactonohydrolase ZHD101. Unlike the lactonohydrolase ZHD101, BsDyP hydroxylated the aromatic ring rather than cleaved the ester bond of the macrolactone ring in ZEN [36]. Meanwhile, it had been reported that the hydroxylation of aromatic moiety in ZEN exhibited a significantly decreased estrogenicity and the estrogenicity of $15-\mathrm{OH}-\mathrm{ZEN}$ was remarkably decreased by 
98\% compared with ZEN [37]. These indicated that it might be a novel strategy feasible for biodetoxification of ZEN by BsDyP from B. subtilis SCK6.

$\mathbf{a}$

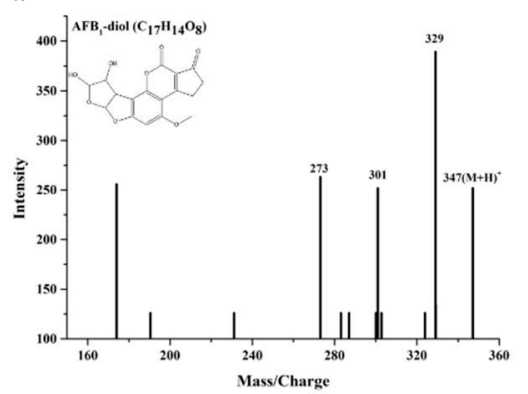

b

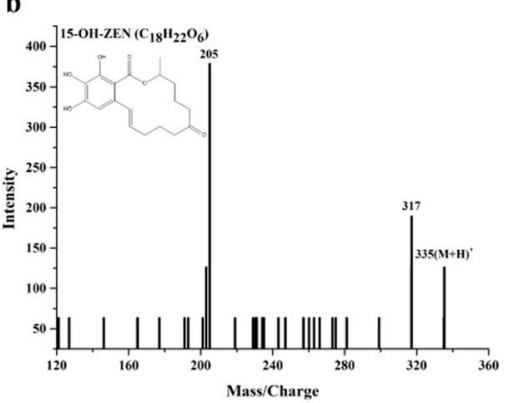

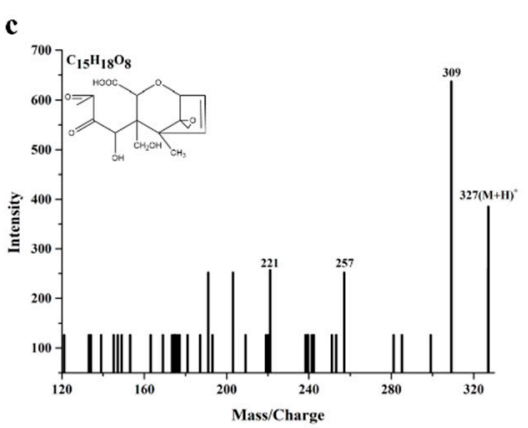

Figure 5. HPLC-MS/MS analysis of AFB1 (a), ZEN (b) and DON (c) degradation products by $1.25 \mathrm{U} / \mathrm{mL}$ BsDyP in $50 \mathrm{mM}$ malonate buffer ( $\mathrm{pH}$ 4.0) supplemented with $1 \mathrm{mM} \mathrm{MnSO}_{4}$ and $0.1 \mathrm{mM} \mathrm{H}_{2} \mathrm{O}_{2}$ at $30{ }^{\circ} \mathrm{C}$ for $48 \mathrm{~h}$.

Although new product peaks of DON degradation by BsDyP appeared in HPLC analysis, only one of the main degradation products was identified by LC-MS/MS, exhibiting a parent ion peak at $\mathrm{m} / \mathrm{z} 327.11[\mathrm{M}+\mathrm{H}]^{+}$. The corresponding daughter ions were $\mathrm{m} / \mathrm{z} 309.09$ $[\mathrm{M}-18+\mathrm{H}]^{+}, 257.10[\mathrm{M}-70+\mathrm{H}]^{+}$and $221.09\left[\mathrm{M}-106+\mathrm{H}^{+}\right.$, which were consistent with the MS/MS fragments of $\mathrm{C}_{15} \mathrm{H}_{18} \mathrm{O}_{8}$ [31]. Although the enzymatic degradation mechanism of $\mathrm{DON}$ by $B s \mathrm{DyP}$ was unclear, the possible structure of the degradation product $\mathrm{C}_{15} \mathrm{H}_{18} \mathrm{O}_{8}$ was shown in Figure $5 \mathrm{c}$. According to structure-activity relationship studies, the toxicity of $\mathrm{C}_{15} \mathrm{H}_{18} \mathrm{O}_{8}$ might be significantly reduced due to the breakage of $\mathrm{C}_{9-10}$ double bond and the loss of $\mathrm{C}_{3}$-hydroxyl group [38]. To our knowledge, this is the first report about biotransformation of multiple mycotoxins, including $\mathrm{AFB}_{1}, \mathrm{ZEN}$ and DON by DyP. Moreover, the biological toxicities of each corresponding enzymatic degradation product, namely AFB1-diol, 15-OH-ZEN and $\mathrm{C}_{15} \mathrm{H}_{18} \mathrm{O}_{8}$, were significantly lower than $\mathrm{AFB}_{1}$, ZEN and DON. Though the other degradation products and their biological toxicity remain to be unveiled, these results might be of great value for practical application of BsDyP in the biodetoxification of multiple mycotoxins in animal feed and food.

\section{Conclusions}

In this study, a dye-decolorizing peroxidase gene was cloned from Bacillus subtilis SCK6, and then successfully expressed in E. coli BL21 as a soluble form, using the cold shock-inducible expression system coupled with co-expression of chaperones. The recombinant $B s$ DyP could oxidize various lignin-derived phenolic compounds and high redox potential synthetic dyes, as well as $\mathrm{Mn}^{2+}$. Moreover, BsDyP could efficiently degrade different types of mycotoxins, including $\mathrm{AFB}_{1}, \mathrm{ZEN}$ and $\mathrm{DON}$, in the presence of $\mathrm{Mn}^{2+}$. The major degradation products of multiple mycotoxins were $\mathrm{AFB}_{1}-$ diol, $15-\mathrm{OH}-$ $\mathrm{ZEN}$ and $\mathrm{C}_{15} \mathrm{H}_{18} \mathrm{O}_{8}$, respectively. The predicted biological toxicity of each corresponding degradation product was significantly removed. Moreover, further studies are needed to confirm the detoxification effects for the pretreatment of contaminated food and animal feed. Nonetheless, the BsDyP exhibited a great application potential for the enzymatic degradation of different types of mycotoxins in animal feed and food.

\section{Material and Methods}

\subsection{Strain and Substrates}

B. subtilis SCK6 was isolated and preserved in Institute of Animal Sciences, Chinese Academy of Agricultural Sciences, Beijing, China. Substrates 2,2'-azino-bis (3-ethylbenzothiazoline-6sulfonic acid) (ABTS), 2,6-dimethylphenol (DMP), guaiacol (GUA), veratryl alcohol (VA), reactive blue 19 (RB19), reactive black 5 (RB5) and mycotoxins, including $\mathrm{AFB}_{1}, \mathrm{ZEN}$ and DON, were purchased from Sigma-Aldrich (St. Louis, MO, USA). Hemin was purchased from TCI (Tokyo, Japan). 


\subsection{Cloning and Expression of BsDyP}

Based on the $5^{\prime}$ and $3^{\prime}$-end sequences of the BsDyP structural gene, the $B s D y P$ was amplified with gene-specific primers (BsDyP-NdeI-F: $5^{\prime}$ ATCATCATATCGAAGGTAGGCATATGAGC GATGAACAGAAAAAGC $3^{\prime}$; BsDyP-Xbal-R: $5^{\prime}$ TTTTAAGCAGAGATTACCTATCTAGATGAT TCCAGCAAACGCTG $3^{\prime}$ ). The PCR product was assembled into the linearized vector $\mathrm{pCold}$ I and then transformed into commercial E. coli BL21/pG-Tf2 chaperone competent cells (Takara, Japan), which harbored a plasmid pG-Tf2 encoding three molecular chaperones: groES, groEL and tig. The cells harboring pCold I-BsDyP were in pre-cultured in LB medium supplemented with $100 \mu \mathrm{g} / \mathrm{mL}$ ampicillin and $20 \mu \mathrm{g} / \mathrm{mL}$ chloramphenicol at $37^{\circ} \mathrm{C}$ overnight and used as the inocula of $300 \mathrm{~mL} \mathrm{LB}$ medium containing $5 \mathrm{ng} / \mathrm{mL}$ tetracyclin, $100 \mu \mathrm{g} / \mathrm{mL}$ ampicillin and $20 \mu \mathrm{g} / \mathrm{mL}$ chloramphenicol. Tetracyclin was used as an inducer for the expression of molecular chaperones. The cultures were grown at $37^{\circ} \mathrm{C}$ for $4 \mathrm{~h}$, followed by the addition of $0.5 \mathrm{mM}$ isopropy- $\beta$-D-thiogalactoside (IPTG) and $20 \mu \mathrm{M}$ hemin for $12 \mathrm{~h}$ induction at $16^{\circ} \mathrm{C}$.

\subsection{Purification and Characterization of $B s D y P$}

After induction, the cells were harvested by centrifugation and resuspended in $30 \mathrm{~mL}$ binding buffer ( $20 \mathrm{mM}$ sodium phosphate, $500 \mathrm{mM} \mathrm{NaCl}, \mathrm{pH}$ 7.4). The cytosol containing the recombinant $B s D y P$ was released by sonication at $130 \mathrm{~W}$ for $30 \mathrm{~min}$. BsDyP was then purified using immobilized metal affinity chromatography with the washing buffer $(20 \mathrm{mM}$ sodium phosphate, $500 \mathrm{mM} \mathrm{NaCl}, 40 \mathrm{mM}$ imidazole, pH 7.4) and elution buffer ( $20 \mathrm{mM}$ sodium phosphate, $500 \mathrm{mM} \mathrm{NaCl}, 200 \mathrm{mM}$ imidazole, $\mathrm{pH}$ 7.4). The purified recombinant $B s$ DyP was verified by SDS-PAGE, using $10 \%$ polyacrylamide gel. The protein content was determined by the Bradford method, using bovine serum albumin as the standard.

The DyP activity was measured by monitoring the oxidation of ABTS $\left(\varepsilon_{420}=36,000 \mathrm{M}^{-1} \cdot \mathrm{cm}^{-1}\right)$ at $420 \mathrm{~nm}$ in the kinetic model by recording absorbance at $30 \mathrm{~s}$ intervals for $5 \mathrm{~min}$, in a buffer containing $50 \mathrm{mM}$ malonate, $1 \mathrm{mM}$ ABTS and $0.1 \mathrm{mM} \mathrm{H}_{2} \mathrm{O}_{2}(\mathrm{pH} 5.0$ and $25^{\circ} \mathrm{C}$ ). One unit of enzyme activity was defined as the amount of enzyme that oxidizes $1 \mu \mathrm{mol}$ of ABTS per min at $25^{\circ} \mathrm{C}$. The purified recombinant $B s \mathrm{DyP}$ was first subjected to UV-visible spectroscopic analysis in the range of 230 to $800 \mathrm{~nm}$ in the $20 \mathrm{mM} \mathrm{pH}$ 5.0 malonate buffer. Then the substrate specificity of BsDyP was studied for the oxidation of different substrates, including ABTS, DMP $\left(\varepsilon_{470}=12,100 \mathrm{M}^{-1} \cdot \mathrm{cm}^{-1}\right)$, GUA $\left(\varepsilon_{465}=49,600 \mathrm{M}^{-1} \cdot \mathrm{cm}^{-1}\right)$, VA $\left(\varepsilon_{310}=9300 \mathrm{M}^{-1} \cdot \mathrm{cm}^{-1}\right), \operatorname{RB} 19\left(\varepsilon_{595}=10,000 \mathrm{M}^{-1} \cdot \mathrm{cm}^{-1}\right)$, RB5 and $\mathrm{Mn}^{2+}\left(\varepsilon_{270}=11,590 \mathrm{M}^{-1} \cdot \mathrm{cm}^{-1}\right)$, in $50 \mathrm{mM}$ sodium malonate buffers with $\mathrm{pH}$ values ranging from 2.0 to 7.0 at $25^{\circ} \mathrm{C}$. The maximum activity of $B s D y P$ was considered to be $100 \%$.

\subsection{Degradation of Different Types of Mycotoxins}

$B s \mathrm{DyP}(1.25 \mathrm{U} / \mathrm{mL})$ was incubated with different types of mycotoxins $\left(\mathrm{AFB}_{1}\right.$ and $\mathrm{ZEN}$ $1 \mu \mathrm{g} / \mathrm{mL}$; DON $10 \mu \mathrm{g} / \mathrm{mL}$ ) in $50 \mathrm{mM} \mathrm{pH} 4.0$ malonate buffer supplemented with $0.1 \mathrm{mM}$ $\mathrm{H}_{2} \mathrm{O}_{2}$ in the presence or absence of $1 \mathrm{mM} \mathrm{MnSO}_{4}$. The reaction was carried out at $30^{\circ} \mathrm{C}$ for $48 \mathrm{~h}$. Periodically, samples were taken out and equal volume methanol were added to stop the reaction.

HPLC analysis of $\mathrm{AFB}_{1}, \mathrm{ZEN}$ and DON degradation were performed by using a SHIMADZU 20A series instrument (Kyoto, Japan) equipped with a UV/Vis detector and RF-20A fluorescence detector with a Waters XBridge C18 column $(5 \mu \mathrm{m}, 4.6 \mathrm{~mm} \times 150 \mathrm{~mm})$. The elution condition for $\mathrm{AFB}_{1}$ was set as follows: $45 \%$ methanol at a flow rate of $0.8 \mathrm{~mL} / \mathrm{min} ; \mathrm{AFB}_{1}$ was monitored at $360 \mathrm{~nm}$ excitation wavelength and $440 \mathrm{~nm}$ emission wavelength. The elution condition for ZEN was set as follows: $45 \%$ acetonitrile (ACN) at a flow rate of $0.8 \mathrm{~mL} / \mathrm{min}$; ZEN was monitored at $274 \mathrm{~nm}$ excitation wavelength and $440 \mathrm{~nm}$ emission wavelength. The elution condition for DON was set as follows: $10 \% \mathrm{ACN}$ at a flow rate of $0.8 \mathrm{~mL} / \mathrm{min}$; DON were monitored at $218 \mathrm{~nm}$.

$\mathrm{AFB}_{1}, \mathrm{ZEN}$ and DON degradation products were further analyzed by using LCMS/MS, which was carried out by coupling a SHIMADZU Nexera UHPLC system (Kyoto, 
Japan) to an AB-SCIEX 5600+ Triple TOF mass spectrometer. For LC analysis, the elution program was as follows: $0-70 \% \mathrm{ACN}, 7 \mathrm{~min} ; 70-100 \% \mathrm{ACN}, 5 \mathrm{~min}$; and $100 \% \mathrm{ACN}, 1 \mathrm{~min}$. For MS analysis, the parameters were set as ion source gases GS1 and GS2 and curtain gas, at 55,55 and 25 psi, respectively; temperature was $500^{\circ} \mathrm{C}$; and ion spray voltage floating was at $5500 \mathrm{~V}$.

Author Contributions: X.Q.: Conceptualization, Methodology, Investigation, Data Curation, Writing-Original Draft, Visualization. X.S.: Conceptualization, Investigation, Methodology. T.T.: Formal analysis, Investigation, Funding acquisition. J.Z.: Investigation, Data Curation, Visualization. X.W.: Validation, Formal analysis. Y.W. (Yaru Wang): Resources, Data Curation. Y.W. (Yuan Wang): Data Curation, Visualization. Y.B.: Resources. B.Y.: Supervision, Funding acquisition. H.L.: Conceptualization, Project administration, Writing—Review \& Editing, Funding acquisition. H.H.: Resources, Investigation, Project administration. All authors have read and agreed to the published version of the manuscript

Funding: This research was supported by the National Key Research and Development Program of China (2021YFC2100200), the State Key Laboratory of Animal Nutrition Project (2004DA125184G2101), and the China Agriculture Research System of MOF and MARA (CARS-41).

Institutional Review Board Statement: Not applicable.

Informed Consent Statement: Not applicable.

Data Availability Statement: The data presented in this study are available on request from the corresponding author.

Conflicts of Interest: The authors declare that they have no competing interests.

\section{References}

1. Pleadin, J.; Frece, J.; Markov, K. Chapter Eight-Mycotoxins in Food and Feed. In Advances in Food and Nutrition Research; Toldrá, F., Ed.; Academic Press: Cambridge, MA, USA, 2019; Volume 89, pp. 297-345.

2. Alshannaq, A.; Yu, J.-H. Occurrence, toxicity, and analysis of major mycotoxins in food. Int. J. Environ. Res. Public Health 2017, 14, 632. [CrossRef]

3. Gruber-Dorninger, C.; Jenkins, T.; Schatzmayr, G. Global mycotoxin occurrence in feed: A ten-year survey. Toxins 2019, 11, 375. [CrossRef]

4. Martins, C.; Assunção, R.; Cunha, S.C.; Fernandes, J.O.; Jager, A.; Petta, T.; Oliveira, C.A.; Alvito, P. Assessment of multiple mycotoxins in breakfast cereals available in the Portuguese market. Food Chem. 2018, 239, 132-140. [CrossRef]

5. Palumbo, R.; Crisci, A.; Venâncio, A.; Cortiñas Abrahantes, J.; Dorne, J.-L.; Battilani, P.; Toscano, P. Occurrence and co-occurrence of mycotoxins in cereal-based feed and food. Microorganisms 2020, 8, 74. [CrossRef] [PubMed]

6. Sobral, M.M.C.; Faria, M.A.; Cunha, S.C.; Ferreira, I.M.P.L.V.O. Toxicological interactions between mycotoxins from ubiquitous fungi: Impact on hepatic and intestinal human epithelial cells. Chemosphere 2018, 202, 538-548. [CrossRef] [PubMed]

7. Ben Taheur, F.; Kouidhi, B.; Al Qurashi, Y.M.A.; Ben Salah-Abbès, J.; Chaieb, K. Review: Biotechnology of mycotoxins detoxification using microorganisms and enzymes. Toxicon 2019, 160, 12-22. [CrossRef]

8. Conte, G.; Fontanelli, M.; Galli, F.; Cotrozzi, L.; Pagni, L.; Pellegrini, E. Mycotoxins in feed and food and the role of ozone in their detoxification and degradation: An update. Toxins 2020, 12, 486. [CrossRef] [PubMed]

9. Li, P.; Su, R.; Yin, R.; Lai, D.; Wang, M.; Liu, Y.; Zhou, L. Detoxification of mycotoxins through biotransformation. Toxins 2020, 12, 121. [CrossRef] [PubMed]

10. Risa, A.; Krifaton, C.; Kukolya, J.; Kriszt, B.; Cserháti, M.; Táncsics, A. Aflatoxin $B_{1}$ and zearalenone-detoxifying profile of Rhodococcus type strains. Curr. Microbiol. 2018, 75, 907-917. [CrossRef] [PubMed]

11. Altalhi, A.D.; El-Deeb, B. Localization of zearalenone detoxification gene(s) in pZEA-1 plasmid of Pseudomonas putida ZEA-1 and expressed in Escherichia coli. J. Hazard. Mater. 2009, 161, 1166-1172. [CrossRef] [PubMed]

12. Singh, J.; Mehta, A. Protein-mediated degradation of aflatoxin $B_{1}$ by Pseudomonas putida. Braz. J. Microbiol. 2019, 50, 1031-1039. [CrossRef] [PubMed]

13. Wang, X.; Qin, X.; Hao, Z.; Luo, H.; Yao, B.; Su, X. Degradation of four major mycotoxins by eight manganese peroxidases in presence of a dicarboxylic acid. Toxins 2019, 11,566. [CrossRef]

14. Wang, X.; Bai, Y.; Huang, H.; Tu, T.; Wang, Y.; Wang, Y.; Luo, H.; Yao, B.; Su, X. Degradation of aflatoxin $B_{1}$ and zearalenone by bacterial and fungal laccases in presence of structurally defined chemicals and complex natural mediators. Toxins 2019, 11, 609. [CrossRef] [PubMed]

15. Gao, X.; Ma, Q.; Zhao, L.; Lei, Y.; Shan, Y.; Ji, C. Isolation of Bacillus subtilis: Screening for aflatoxins $\mathrm{B}_{1}, \mathrm{M}_{1}$, and $\mathrm{G}_{1}$ detoxification. Eur. Food Res. Technol. 2011, 232, 957. [CrossRef] 
16. Cho, K.J.; Kang, J.S.; Cho, W.T.; Lee, C.H.; Ha, J.K.; Song, K.B. In vitro degradation of zearalenone by Bacillus subtilis. Biotechnol. Lett. 2010, 32, 1921-1924. [CrossRef] [PubMed]

17. Min, K.; Gong, G.; Woo, H.M.; Kim, Y.; Um, Y. A dye-decolorizing peroxidase from Bacillus subtilis exhibiting substrate-dependent optimum temperature for dyes and $\beta$-ether lignin dimer. Sci. Rep. 2015, 5, 8245. [CrossRef] [PubMed]

18. Alfi, A.; Zhu, B.; Damnjanović, J.; Kojima, T.; Iwasaki, Y.; Nakano, H. Production of active manganese peroxidase in Escherichia coli by co-expression of chaperones and in vitro maturation by ATP-dependent chaperone release. J. Biosci. Bioeng. 2019, 128, 290-295. [CrossRef] [PubMed]

19. de Eugenio, L.I.; Peces-Pérez, R.; Linde, D.; Prieto, A.; Barriuso, J.; Ruiz-Dueñas, F.J.; Martínez, M.J. Characterization of a dye-decolorizing peroxidase from Irpex lacteus expressed in Escherichia coli: An enzyme with wide substrate specificity able to transform lignosulfonates. J. Fungi 2021, 7, 325. [CrossRef] [PubMed]

20. Linde, D.; Coscolín, C.; Liers, C.; Hofrichter, M.; Martínez, A.T.; Ruiz-Dueñas, F.J. Heterologous expression and physicochemical characterization of a fungal dye-decolorizing peroxidase from Auricularia auricula-judae. Protein Expr. Purif. 2014, $103,28-37$. [CrossRef]

21. Catucci, G.; Valetti, F.; Sadeghi, S.J.; Gilardi, G. Biochemical features of dye-decolorizing peroxidases: Current impact on lignin degradation. Biotechnol. Appl. Biochem. 2020, 67, 751-759. [CrossRef]

22. Qin, X.; Luo, H.; Zhang, X.; Yao, B.; Ma, F.; Su, X. Dye-decolorizing peroxidases in Irpex lacteus combining the catalytic properties of heme peroxidases and laccase play important roles in ligninolytic system. Biotechnol. Biofuels 2018, 11, 302. [CrossRef] [PubMed]

23. Janusz, G.; Kucharzyk, K.H.; Pawlik, A.; Staszczak, M.; Paszczynski, A.J. Fungal laccase, manganese peroxidase and lignin peroxidase: Gene expression and regulation. Enzym. Microb. Technol. 2013, 52, 1-12. [CrossRef] [PubMed]

24. Knop, D.; Levinson, D.; Makovitzki, A.; Agami, A.; Lerer, E.; Mimran, A.; Yarden, O.; Hadar, Y. Limits of versatility of versatile peroxidase. Appl. Environ. Microbiol. 2016, 82, 4070-4080. [CrossRef] [PubMed]

25. Fernández-Fueyo, E.; Linde, D.; Almendral, D.; López-Lucendo, M.F.; Ruiz-Dueñas, F.J.; Martínez, A.T. Description of the first fungal dye-decolorizing peroxidase oxidizing manganese(II). Appl. Microbiol. Biotechnol. 2015, 99, 8927-8942. [CrossRef] [PubMed]

26. Santos, A.; Mendes, S.; Brissos, V.; Martins, L.O. New dye-decolorizing peroxidases from Bacillus subtilis and Pseudomonas putida MET94: Towards biotechnological applications. Appl. Microbiol. Biotechnol. 2014, 98, 2053-2065. [CrossRef]

27. Chen, C.; Shrestha, R.; Jia, K.; Gao, P.F.; Geisbrecht, B.V.; Bossmann, S.H.; Shi, J.; Li, P. Characterization of dye-decolorizing peroxidase (DyP) from Thermomonospora curvata reveals unique catalytic properties of A-type DyPs. J. Biol. Chem. 2015, 290, 23447-23463. [CrossRef]

28. Linde, D.; Ruiz-Dueñas, F.J.; Fernández-Fueyo, E.; Guallar, V.; Hammel, K.E.; Pogni, R.; Martínez, A.T. Basidiomycete DyPs: Genomic diversity, structural-functional aspects, reaction mechanism and environmental significance. Arch. Biochem. Biophys. 2015, 574, 66-74. [CrossRef] [PubMed]

29. Loi, M.; Renaud, J.B.; Rosini, E.; Pollegioni, L.; Vignali, E.; Haidukowski, M.; Sumarah, M.W.; Logrieco, A.F.; Mulè, G. Enzymatic transformation of aflatoxin B1 by Rh_DypB peroxidase and characterization of the reaction products. Chemosphere 2020, 250, 126296. [CrossRef]

30. Wang, X.; Yao, B.; Su, X. Linking enzymatic oxidative degradation of lignin to organics detoxification. Int. J. Mol. Sci. 2018, 19, 3373. [CrossRef] [PubMed]

31. Li, M.; Guan, E.; Bian, K. Structure elucidation and toxicity analysis of the degradation products of deoxynivalenol by gaseous ozone. Toxins 2019, 11, 474. [CrossRef] [PubMed]

32. Li, J.; Huang, J.; Jin, Y.; Wu, C.; Shen, D.; Zhang, S.; Zhou, R. Aflatoxin B1 degradation by salt tolerant Tetragenococcus halophilus CGMCC 3792. Food Chem. Toxicol. 2018, 121, 430-436. [CrossRef] [PubMed]

33. Slobodchikova, I.; Sivakumar, R.; Rahman, M.S.; Vuckovic, D. Characterization of phase I and glucuronide phase II metabolites of 17 mycotoxins using liquid chromatography-high-resolution mass spectrometry. Toxins 2019, 11, 433. [CrossRef] [PubMed]

34. Iram, W.; Anjum, T.; Iqbal, M.; Ghaffar, A.; Abbas, M. Structural elucidation and toxicity assessment of degraded products of aflatoxin $\mathrm{B}_{1}$ and $\mathrm{B}_{2}$ by aqueous extracts of Trachyspermum ammi. Front. Microbiol. 2016, 7, 346. [CrossRef]

35. Wang, J.; Ogata, M.; Hirai, H.; Kawagishi, H. Detoxification of aflatoxin B1 by manganese peroxidase from the white-rot fungus Phanerochaete sordida YK-624. FEMS Microbiol. Lett. 2011, 314, 164-169. [CrossRef]

36. Takahashi-Ando, N.; Kimura, M.; Kakeya, H.; Osada, H.; Yamaguchi, I. A novel lactonohydrolase responsible for the detoxification of zearalenone: Enzyme purification and gene cloning. Biochem. J. 2002, 365, 1-6. [CrossRef]

37. Drzymala, S.S.; Binder, J.; Brodehl, A.; Penkert, M.; Rosowski, M.; Garbe, L.-A.; Koch, M. Estrogenicity of novel phase I and phase II metabolites of zearalenone and cis-zearalenone. Toxicon 2015, 105, 10-12. [CrossRef]

38. He, J.; Zhou, T.; Young, J.C.; Boland, G.J.; Scott, P.M. Chemical and biological transformations for detoxification of trichothecene mycotoxins in human and animal food chains: A review. Trends Food Sci. Technol. 2010, 21, 67-76. [CrossRef] 